\title{
A MUSICALIDADE EM NICOLÁS GUILLÉN
}

Elena Godoy*

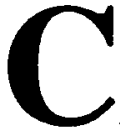

omo sabemos, um dos pontos principais da poesia de Guillén é a sua preocupação com o nacional cubano. Nas primeiras décadas do século XX, a pergunta de José Martí "Como somos?" resolve-se, em Cuba, em termos da reflexão cultural da época e produz uma verdadeira crise de representação. A crise se relaciona com o aristocratismo geral do modernismo hispanoamericano do início do século. A imagem da América Latina precisava de uma reformulação. Os Motivos de son (1930) de Guillén representam uma ruptura com a última fase do modernismo. Mas, por outro lado, quase que paradoxalmente, Guillén se mostra, de uma maneira peculiar, imerso em certas tendências estilísticas que remetem à vanguarda e ao chamado pós-modernismo hispano-americano. Essas ressonâncias da vanguarda se concentram, em primeiro lugar, na musicalidade do verso, que se desenvolve de uma maneira específica: "El vanguardista no fue, ni en Cuba ni en Europa, un impugnador sistemático del ritmo poético, sino del ritmo gastado de la poesía al uso (...) Los Motivos de son proponen así, un ritmo inédito en nuestra lírica, un ritmo escandaloso e inesperado que, precisamente, era el ritmo del pueblo." (Rodríguez Rivera, 1982, p. 68).

Assim, a experimentação rítmica em Motivos de son procurou resgatar a profunda dívida com a música popular cubana, fazendo com que esses breves poemas se apresentassem como uma maneira alegre e um tanto irresponsável de fazer o costumbrismo. Como notam Álvarez Álvarez e García Yero,

* Universidade Federal do Paraná. 
no hay por qué rechazar por completo la idea de que la tradición costumbrista de la literatura cubana del siglo anterior haya ejercido cierto atractivo en Guillén; al fin y al cabo, nada mejor para un joven poeta - o de cualquier edad - que conocer y aprovechar las lecciones del pasado literario de su patria, y aun fuera de ella. El interés por el colorido, la visión escorzada de una anécdota que apenas se insinúa - sea en el poema, la narración, el cuadro, la canción o la crónica periodística - fueron ingredientes centrales de la gracia, hasta hoy durable, del costumbrismo decimonónico cubano (1995, p. 56).

Ao mesmo tempo, a aproximação do popular, na época, coincide com o interesse do movimento vanguardista, em particular na Espanha, pelo resgate da dignidade da cultura popular: basta lembrar a tendência "neopopularista" de Federico García Lorca com seus ciclos El poema del cante jondo e Romancero gitano. Vale lembrar também que Lorca visitou Havana em 1930, onde deu várias palestras que desenvolvem suas idéias sobre a relação entre a poesia e a música popular. Assim, pode-se pensar numa espécie de paralelismo das preocupações dos dois poetas em buscar uma identificação tangível de uma cultura popular e o papel que nela desempenham as camadas tradicionalmente marginalizadas ("obscuras", nas palavras de Lorca).

Durante todo o período colonial, o folclore espanhol e o negro se desenvolviam, em Cuba, simultânea e paralelamente, mas sempre se encontrando e interagindo. Essa interação entre duas culturas musicais (a "transculturação") levou ao aparecimento de uma nova música: a afro-cubana, que conjuga as melodias, os metros, os instrumentos e os ritmos espanhóis com as tradições musicais africanas.

Nos Motivos de son, Guillén se delicia e "brinca" com as estruturas rítmicas do verso. Essas estruturas dialogam com a música popular de duas maneiras: o ritmo propriamente poético remete a outra linguagem rítmica por excelência, que é a música; os versos de Guillén evocam os textos dos sones, que é um gênero musical. Mas por quê exatamente $o$ son? Que música é esta? De acordo com Alejo Carpentier (que, não esqueçamos, além e antes de tornar-se um dos melhores escritores que a América Hispânica já teve, foi musicólogo), el son, con sus instrumentos típicos, es uno de los más ricos frutos del folklore musical que puedan imaginarse. Su aire es inconfundible, y su elocuencia rítmica es aplastante no tanto por la diversidad y riqueza de su percusión, sino por el 
modo completamente inusitado con que ésta aparece utilizada. Lo prodigioso de esa música estriba en que es esencialmente "polirrítmica". (1994, p. 229)

O son chegou, ou melhor, invadiu a Havana pelo ano de 1820 , mas tinha nascido bem antes, provavelmente no século XVI (ou seja, quando começaram a chegar - claro que não voluntariamente - os escravos africanos) na província de Oriente. Nos séculos XVI e XVII, a palavra son significava, em Cuba, qualquer música popular "dançável". Tal como aconteceu também mais tarde com a rumba e hoje com a salsa, vários estilos e até variações rítmicas e instrumentais cabem dentro do termo. Antes de serem gêneros musicais, esses "gêneros" são uma espécie de "climas" (atmósferas, nas palavras de Carpentier; Rodrígues Rivera, 1982, p. 231) e não gêneros perfeitamente definíveis. Mas o son tem mais uma característica muito especial. Dentro de cada tempo musical, cada instrumento de percussão leva "sua vida autônoma", mantém seu ritmo específico. É essa pluralidade rítmica, ainda submetida a uma unidade de tempo, que forma uma verdadeira polirritmia mencionada por Carpentier. Acrescente-se a isso que o son, além de ser uma música “dançável”, também era - e ainda é - uma música "cantável". Um dos primeiros sones de que se têm registros é o son de Ma'Teodora que conta - e canta - a morte e o funeral da figura folclórica conhecidíssima em Cuba, que é Papá Montero (esse son é recontado - ou "recantado"? - por Guillén em Sóngoro Cosongo, 1931). E, tal como nas antigas formas primitivas das canções iorubas e bantos, no son original, há uma voz solo e um coro que se alternam. Mas também, tal como nas antigas cerimônias funerais e religiosas africanas, as respostas do coro às variações do solo se reiteram - em princípio ad infinitum -e o ritmo pode acelerar-se:

Coro: A llorar a Papá Montero.

¡Zumba!

Canalla rumbero.

Solo: Lo llevaron al agujero.

Coro: ¡Zumba!

Canalla rumbero.

Solo: Nunca más se pondrá sombrero.

Coro: ¡Zumba!

Canalla rumbero...

O son cubano mistura as características das canções tradicionais bantos e iorubas. Nas canções bantos, predominam frases - lingüísticas e musicais curtas, enquanto nas iorubas, as frases musicais são mais longas e as escalas 
mais variadas. É esse son e essa polirritmia, são essas reiterações, que hipnotizam como hipnotiza um ritual mágico africano, que se encontram e são exploradas na poesia de Guillén. Vejamos:

CANTO NEGRO (Motivos del son, 1930)

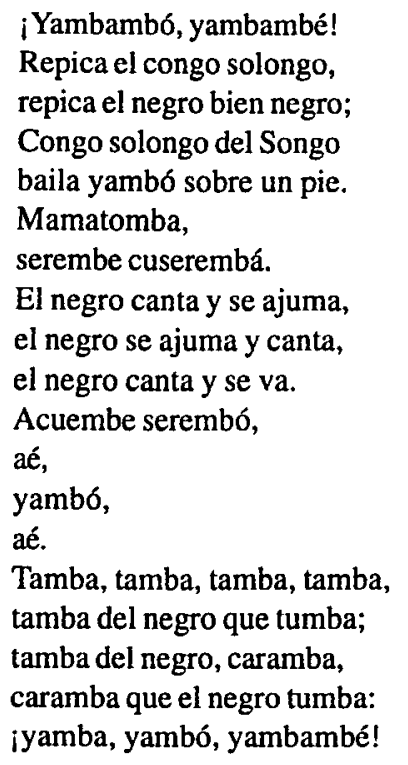

Os versos desse poema são polimétricos, contendo uma espécie de "pie quebrado" irregular. A rima também é irregular: ora consoante, como nas canções populares, ora aparentemente nenhuma, mas com uma forte marcação de mudança de sílaba tônica. Lembrando as palavras de Fernández Retamar, poderíamos dizer que se trata de "ejemplos admirables del tipo de versificación estudiada por Pedro Henríquez Ureña bajo el nombre de acentual, con número fluctuante de sílabas, pero con acentuación de efectos definidos, relacionados con la música" (Retamar; 1994, p. 181).

A polirritmia se processa em vários níveis: há reiterações lexicais (repica el...; (d)el negro...; tamba... etc.), há reiterações de construções sintáticas inteiras (el negro V y V...) e, além disso, também há reiterações no interior das palavras (- mb - ...; yamb- ...; seremb- ...; - ongo...). Ou seja, as reiterações se produzem simultaneamente em vários níveis linguiísticos, formando uma estrutura rítmica extraordinariamente complexa. 
Dessa maneira, a organização rítmica da poesia de Guillén se constrói a partir de uma concepção audaz e refinadíssima do ritmo que tem muito de vanguardista. Por outro lado, há nos poemas de Guillén, tal como nos de outros cultivadores da "poesia negra" (E. Ballagas, L. Palés Matos, entre outros), um jogo fonético-estilístico que é chamado de jitanjáfora (tamba, mayombé, cuserembá etc.). São palavras que não existem em língua alguma (muito menos em espanhol), que não significam nada mais ou menos identificável, tendo um referente extremamente vago, uma espécie de "suprarreferente". Ou seja, as jitanjaforas, com sua "cara" de palavras de alguma língua africana, remetem invariavelmente a algo "afro". Esse "suprarreferente afro" também se faz presente na métrica e no ritmo: os versos longos e curtos misturam as tradições musicais iorubas e bantos e as insistentes reiterações "traem" a origem africana da inconfundível música cubana (ou, melhor, de toda a música caribenha).

Ao analisar a poesia de Guillén, D. Navarro fez o levantamento estatístico dos fonemas com traço [+ labial] utilizados nos poemas dos Motivos de son: $/ \mathrm{m} /, / \mathrm{b} /, / \mathrm{p} /, / \mathrm{o} / \mathrm{e} / \mathrm{u} /$. Os fonemas com esse traço aparecem "en distintos poemas de ese libro con una frecuencia global mucho mayor que en el español 'normal' de periódicos y conversaciones cotidianas" (1988, p. 23). Se no espanhol "normal" a porcentagem de frequiência desses fonemas é entre $15 \%$ e $20 \%$, nos Motivos de son há poemas, nos quais essa porcentagem sobe até $30 \%$. Navarro observa que

en diversos textos no-poéticos escritos no sólo en yoruba y efik, sino también en kikongo (...) hemos hallado que la abundancia relativa de los fonemas labiales asciende (...) a una proporción que oscila alrededor del $30 \%$ (es decir, el doble o casi el doble de su porcentaje en el español corriente). Así pues, en poemas como "Búcate plata", "Si tú supiera..." o "Negro bembón", Guillén le ha conferido al idioma español una textura fónica de esas lenguas negro-africanas. Diríase que en ellos, al hablar español, el poeta está hablando también en una lengua negro africana" (Navarro, 1988).

Assim, os poemas de Guillén se revelam como textos ritmicamente organizados numa direção muito especial: a textura fônica, cuja base léxico-sintática é o espanhol, se aproxima não de alguma língua africana, mas de uma espécie de uma imagem supraindividual, a uma "arquiafricania" lingüística integrada por traços de várias línguas africanas específicas. Continua Navarro: 
En varios poemas de Guillén se observa la frecuente aparición de las combinaciones mb, mp, ng y nd. Ya hemos señalado el papel de éstas en la formación de onomatopeyas de tambor. Pero el hecho de que esas combinaciones sean muy frecuentes en la lengua kikongo y de que figuren en la mayoría de los vocablos africanóides creados por Guillén ("sóngoro cosongo", "solongo del Songo", "mamatomba serembe cuserembá", etcétera), nos conduce a la idea de que esas combinaciones fonemáticas cumplen una doble función: onomatopéyica y estilizacional (Navarro, 1988, p. 26).

O curtíssimo poema "Caña" contém apenas quatro estrofes, três das quais são sintagmas nominais (não contêm verbos) que repetem a mesma estrutura: Art + Subst + Prep + Art + Subst, em que o último substantivo se reitera, insistindo, "martelando" no "centro vital" que é o canavial. As preposições marcam - porque são as únicas que mudam nos versos pares das estrofes - a posição espacial e hierárquica (ao lado, em cima e embaixo) dos substantivos"personagens". A última estrofe, com versos mais curtos, muda também sua estrutura: o primeiro substantivo não traz o artigo além de ser expandido por uma sentença relativa. Essa quebra do ritmo em dois níveis destaca o "sangramento" da gente da terra ("nos") de todos os tempos ("se...va" com o verbo cliticizado (irse e não ir), marcando uma ação sem volta e no presente ("atemporal"). Vejamos:

\author{
Caña (Sóngoro Cosongo, 1931) \\ El negro \\ junto al cañaveral. \\ El yanqui \\ sobre el cañaveral.
}

La tierra

bajo el cañaveral.

¡Sangre

que se nos va!

Esse princípio de polirrítmia musical se mantém nos ciclos poéticos posteriores. $\mathrm{Na}$ "Canción puertorriqueña", é fácil encontrar uma boa parte dos 
procedimentos poéticos comentados. Entretanto, observe-se a virtuosidade da técnica do refrão, que é um verdadeiro "tema com variações" em vários níveis: lexical, sintático e prosódico/rítmico:

\section{Canción puertorriqueña (La paloma de vuelo popular, 1958)}

¿Cómo estás, Puerto Rico, tú, de socio asociado en sociedad?

Al pie de cocoteros y guitarras, bajo la luna y junto al mar, ¡qué suave honor andar del brazo, brazo con brazo del Tío Sam! ¿En qué lengua me entiendes, en qué lengua por fin te podré hablar?

¿si en yes, si en sí, si en bien, si en well, si en mal, si en bad, si en very bad?

Juran los que te matan que eres feliz... ¿Será verdad?

Arde tu frente pálida, la anemia en tu mirada logra un brillo fatal; no bien, masticas una jerigonza medio española, medio slang; de un empujón de hundieron en Corea, sin que supieras por quien ibas a pelear, si en yes, si en sí si en bien, si en well, si en mal, si en bad, si en very bad!

Ay, yo bien conozco a tu enemigo, el mismo que tenemos por acá, socio en la sangre y el azúcar, socio asociado en sociedad: United States and Puerto Rico, es decir New York City with SanJuan, Manhattan y Borinquen, soga y cuello, Apenas nada más...

¡No yes, no sí, no well símal, sí bad, sí very bad!

O refrão repete o jogo lingüístico (ou seria melhor dizer: linguiístico-ideológico?) de "alterações de código" (code switchings): espanhol/inglês (una jerigonza medio española, medio slang), lembrando que Porto Rico foi anexado aos Estados Unidos em 1898, depois da guerra entre os Estados Unidos e Espanha, tornando-se um Estado americano bilíngüe. A lembrança dessa situação vergonhosa e desastrosa do irmão caribenho é, na verdade, o tema desse poema, e Guillén é amargamente irônico quando diz: "qué suave honor andar del brazo, brazo a brazo com Tio Sam"; "sócio (en la sangre y el azúcar,socio) asociado em sociedad", etc. Pois, o jogo dos refrões se baseia justamente nesse bilingüismo imposto a um povo hispano-americano (a "jerigonza"), nas repetições da su- 
posta afirmação (si/yes) e na oposição bien/well x mal/bad, formando uma dupla oposição. Essa oposição se reitera com variações também em diversos níveis: prosódico (interrogação $x$ exclamação), sintático com os advérbios aparecendo preposicionados em dois refrões com sete repetições em cada, e sem as preposições no último refrão, e semântico com a variação no último refrão apresentando quatro negações do pólo positivo (no sí, no yes, no bien, no well) e três afirmações do pólo negativo (sí mal, si bad, sí very bad). Os três níveis entram em mais uma variação no último verso de cada refrão, com a inserção do advérbio very. O resultado desse "jogo" é uma musicalidade característica de ritmos perfeitamente caribenhos, mestiços, como são as pachangas, rumbas, cha-chachas, salsas, etc.etc., todas filhas do velho son afro-cubano.

Dessa maneira, aparecem na poesia de Guillén simultaneamente várias espécies - complexas e entrelaçadas - de intertextualidade: se "convocam" os textos africanos nos níveis lingüístico e musical, além dos textos da linguagem coloquial das ruas de Havana e da sua música "mulata". Com isso, se redefine a imagem cultural de mestiçagem profunda com sua musicalidade esplêndida.

\section{RESUMO}

O objetivo deste artigo é mostrar que as características da musicalidade notadamente específica da poesia de Nicolás Guillén se organizam de uma maneira complexa em vários níveis lingüísticos através das múltiplas "vozes" de múltiplos textos, formando uma verdadeira mestiçagem, a "mulatez" sonhada e defendida pelo poeta. Guillén.

Palavras-chave: literatura hispano-americana, cultura caribenha, Nicolás

\section{RESUMEN}

Este artículo objetiva demostrar que las características de la musicalidad específica de la poesía de Nicolás Guillén se organizan de un modo complejo en varios niveles lingüísticos a través de múltiples "voces" de múltiples textos, que forman un verdadero mestizaje, la "mulatez" soñada y defendida por el poeta.

Palabras-clave: literatura hispanoamericana, cultura caribeña, Nicolás Guillén. 


\section{REFERÊNCIAS}

ÁlVAREZ ÁlVAREZ, L. y O. García Yero. Hispanidad y vanguardia en Guillén. Revolución y Cultura, año 34, n. 3, p. 53-56, mayo/jun. 1995.

CARPENTIER, A. Temas de la lira y del bongó. La Habana: Letras Cubanas, 1994.

FERNÁNDEZ RETAMAR, R. El son del vuelo popular. In: MOREJÓN, N. (Org.) Nicolás Guillén. La Habana: Casa de las Américas, 1994.

GUILLÉN, N. Sóngoro Cosongo y otros poemas. Selección del autor. Madrid: Alianza, 1981.

NAVARRO, D. Ejercicios del criterio. La Habana: Unión, 1988.

RODRÍGUEZ RIVERA, G. Nicolás Guillén y el vanguardismo. Revista de Literatura Cubana, año 1, p. 59-70, 1982. 